Journal of the Scholarship of Teaching and Learning, Vol. 21, No. 1, April 2021, pp. 225-240.

doi: 10.14434/josotl.v21i1.30359

\title{
QEP is HIP: A Case Study Implementing an Institution-Wide Undergraduate Research Community of Inquiry for a Small Private College Setting
}

\author{
Melissa N. Tingle \\ Piedmont College \\ mtingle@piedmont.edu \\ Julia M. Schmitz \\ Piedmont College \\ jschmitz@piedmont.edu \\ Perry Rettig \\ Piedmont College \\ prettig@piedmont.edu
}

\begin{abstract}
Piedmont College's quality enhancement plan (QEP) emphasizes a developmental and progressive integration of high-impact practices (HIPs) into the academic and social fabric of the institution. The QEP is HIP initiative provides students with multiple opportunities to deepen learning and leadership skills, which leads to improvements in student success, persistence, and retention. However, the institution grappled with how to effectively engage students in effective, meaningful research-based experiences. During the 2nd year of its QEP implementation, a campuswide undergraduate research symposium was launched to showcase students' research and creative inquiry in an effort to (a) gain full institutional participation in this crucial HIP and (b) offer the underserved student population (defined as ethnic minority, Pell-eligible, and first-generation students) an opportunity to participate in professional socialization and experience faculty mentorship. This case study shows the initial influences of this HIP on student success (in terms of grade point average [GPA]), students' perceptions of their own learning, students' persistence (measured with the Grit Scale), and retention from the 2018-2019 to the 2019-2020 academic year. Specifically, this study compared students who presented their research at the undergraduate research symposium to students who did not. While the immediate influence of this HIP on student persistence/perseverance (grit scores) remains undetermined, the retention rates and GPA appear to have been higher for students who presented, in both the dominant and underserved populations. Furthermore, students reported an increase in perceptions of their own learning. These findings are significant and affirm that undergraduate research communities can be considered a HIP for students, including those of underserved populations.
\end{abstract}

Keywords: quality enhancement plan (QEP), high-impact practice, undergraduate research, symposium

Institutions of higher learning across the nation are focusing on increasing student retention and persistence to graduation by integrating high-impact practices (HIPs), particularly undergraduate research. Undergraduate research, a form of experiential learning, connects key concepts and questions with students' early and active involvement in systematic investigation and research (Kuh, 2008). Effectively integrating a culture of research across different departments and programs within an institution, however, is challenging. "Promoting a culture of research across campus requires some form of institutional consensus and a common focus to help achieve this objective" (Nyhus, Cole, Yeterian, \& Firmage, 2002, p. 16). Along with this focus comes the problem of implementation: While 
many institutions have focused on undergraduate research experiences (UREs) at the course and programmatic levels in recent years (Fechheimer, Webber, \& Kleiber, 2011), resources must also be dedicated to developing an institution-wide culture that showcases these high-impact research practices outside the classroom. Furthermore, special care must be taken in the creation of this undergraduate research community of inquiry to engage historically underserved student populations, increase students' perceptions of their own learning, and encourage a "cross-pollination" approach to research between the disciplines and fields within an institution (Dhand, Luke, Carothers, \& Evanoff, 2016).

\section{Background}

This case study focuses on a small private college in northeast Georgia that is a member of the Southern Association of Colleges and Schools Commission on Colleges. Recently tasked with developing a quality enhancement plan (QEP) to implement institution-wide HIPs, the college chose to center its efforts on integrating undergraduate research and creative inquiry into the academic and social fabric of the institution. In its first year, the "QEP is HIP" initiative provided students and faculty with multiple funding opportunities to deepen learning and research skills; however, the institution grappled with how to effectively engage students across disciplines in effective, meaningful, research-based experiences to realize tangible improvements in student success, persistence, and retention (Bonet \& Walters, 2016; Kelly, 2011). While departments throughout the college had already experienced some success with integrating UREs at the course and programmatic levels, a collective undergraduate research community was needed to offer students the opportunity to display and discuss research outside the traditional classroom, receive interdisciplinary feedback, and develop an institutional culture of transformational research experiences, particularly aimed at its underserved student population.

In response to this problem, during the 2nd year (2018-2019) of its QEP implementation, the college launched a campus-wide undergraduate research symposium to showcase students' research and creative inquiry. This was in an effort to (a) gain full institutional participation in this crucial HIP and (b) offer the underserved student population (defined as ethnic minority, Pell-eligible, and firstgeneration students) an opportunity to participate in professional socialization and experience faculty mentorship that provides "leadership to their own learning and the learning of others" (Camacho, Holmes, \& Wirkus, 2015, p. 65). As part of the symposium implementation process, the QEP director, along with a specialized symposium steering committee, created a planning document that mapped out a timeline of development and execution.

\section{Timeline and Implementation}

The symposium steering committee was created in January 2018 with representatives from the four schools at Piedmont College (Arts \& Sciences, Business, Education, and Nursing \& Health Sciences), as well as a communications director and experiential learning director. The steering committee met to formulate initial symposium plans with a target launch date of April 2019. Four months later, the group traveled to a peer southeastern institution to experience its undergraduate research day firsthand. This helped the committee formulate ideas regarding the logistics and delivery of a similar event as well as gave individuals the opportunity to sit down with the research day organizers and ask questions to help frame their own research day. Later that month, an additional communications committee was created, which settled on the name of the undergraduate research day to begin the branding and promotion process, led by the communications director from the symposium steering committee. Last, a QEP assessment committee, which had been created as part of the overall QEP

Journal of the Scholarship of Teaching and Learning, Vol. 21, No. 1, April 2021.

josotl.indiana.edu 
initiative, was tasked with developing direct and indirect assessment tools, so that the relationship between symposium participation, retention, engagement, and other HIP outcomes could be assessed.

In fall 2018, a renowned research professor was invited from a different peer institution to generate interest in the research day. She presented to students and faculty in various sessions and conducted small groups for students to develop ideas for a research question and then formulate what type of research they would need to complete to answer that research question, which they then presented to the larger group. This visit was integral to preparations for the research day because it helped prime students and faculty to consider an institutional research symposium and prompted them to "think outside the box" for types of projects they could develop from current course content and assignments. The symposium steering committee also launched an online application process during her visit, so students could begin submitting project abstracts and proposals. Additionally, information was made available to faculty about the accessibility of QEP research grants to help fund research proposals. The steering committee concurrently worked with the academic deans as well as heads of different key cocurricular projects (e.g., Summer Travel Study, Alternate Spring Break, Experiential Learning), to develop participation goals for the number of students they would enlist from each specific area. This encouraged collaboration between the steering committee and the various institutional heads to achieve a higher percentage of participation and overall buy-in. Additionally, the steering committee worked with the vice-president for academic affairs to arrange for all afternoon classes to convene at the half-day event, to increase attendance numbers and support for student participants.

The online application process concluded at the end of February 2019, and students were notified in class (by their professor) the following month with an embossed recognition card announcing their selection. The reason for this was threefold: (1) The student received public acknowledgement of this achievement they could archive in their professional portfolio; (2) it offered the advising professor an opportunity to talk about the importance of participating in the research day to support their fellow student participants; and (3) it created a subtle air of prestige surrounding the event.

Two weeks before the scheduled symposium event, the QEP assessment committee presented digital rubrics (adapted from the Association of American Colleges and Universities' [AAC\&U's] Integrative Learning VALUE Rubric) and procedures for assessing presentations and research posters. The communications committee also selected a few presentations to highlight ahead of the event to increase the interest of students attending the event. The steering committee procured volunteers from faculty and staff to serve as assessors for each presentation and poster. Student volunteers were recruited to be runners, timekeepers, and welcome -table workers to ensure all participants were checked in for the event.

On the event day, each student who participated received a certificate and an official event shirt during check-in. The institutional advancement media team was on hand to take pictures and create a video that was released the following day on various institutional web and social media outlets. Student influencers were also selected to take over social media and post in real time about the event to allow parents, alumni, and prospective students who were unable to attend the opportunity to feel included and connected to the event. The student-run radio station ran a live on-site broadcast throughout the day and interviewed members of the committee, as well as various student participants, so they could discuss their event roles and create a buzz of excitement.

After the event concluded, several debriefing processes took place. The assessment committee collected all assessment data from the digital rubrics and merged it into the primary QEP database. The communications and steering committees convened the week following the event to discuss the anecdotal feedback from faculty, students, and administrators as well as compile a list of logistical improvements to consider for the next symposium. Discussions about the level of academic rigor of student presentations ensued, and a recommendation for additional library resources and research

Journal of the Scholarship of Teaching and Learning, Vol. 21, No. 1, April 2021. josotl.indiana.edu 
workshops was offered. Additionally, a feature article was written by the Office of Institutional Advancement for its Academic Showcase Journal, which was then delivered to alumni, parents, faculty, staff, and current students, providing an official post-event record.

\section{Literature Review}

The idea for this institution's undergraduate research day originated from the AAC\&U's LEAP (Liberal Education and America's Promise) initiative, developed in 2005. One aspect of this initiative is the inclusion of HIPs as identified by George Kuh (2008), who has advocated for institution-wide UREs. The AAC\&U (2020) noted that HIPs increase rates of student retention and engagement. Additionally, "high impact practices have a pronounced effect on the experiences of underserved students" (Finley \& McNair, 2013, p. 13). The institution was specifically interested in building upon ideas presented in extant URE literature to increase student persistence, retention, engagement, and overall academic success.

\section{UREs and Student Persistence/Retention}

Undergraduate research is an HIP that leads to better student achievement, retention, and persistence (Bonet \& Walters, 2016; Craney et al., 2011). It has a pronounced impact on underrepresented populations, leads to deeper learning, and can build a professional community through mentoring (Bonet \& Walters, 2016; Kelly, 2011). While undergraduate research projects have typically been employed within the "hard sciences," Kuh (2008) recognized that opportunities to engage in undergraduate research can, and increasingly do, exist in all academic disciplines. According to Kuh (2008), the goal of undergraduate research is to "involve students with actively contested questions, empirical observations, cutting-edge technologies, and the sense of excitement that comes from working to answer important questions" (p. 10). Cooper et al. (2019) also focused on the benefits and value of being involved in undergraduate research. They found that students persisted with their research because they "perceived they were learning important skills or knowledge and because they perceived it was important for their career goals" (Cooper et al., 2019, p. 19). Tinto (1975) studied the reasons students leave college early and found that those who persisted were better integrated into formal classroom experiences, such as undergraduate research, and interacted with faculty at a higher rate. Furthermore, he argued that to persist in their studies, students require not just formal and informal classroom experiences but also integration into the formal social systems of an institution (Tinto, 1975).

\section{UREs and Student Engagement/Perceptions of Learning}

Student involvement in undergraduate research, with both faculty and peers, has a wide-ranging impact on student engagement and perceptions of their own learning. Astin (1999) noted that students who invest significant time and energy into being actively engaged within their academic experiences are more likely to persist. Kinner and Lord (2018) found that upper level students who had high levels of engagement in UREs had significantly higher gains in "feeling like a scientist," creativity, working extra hours, and feeling part of a scientific community. With respect to working with faculty and other student mentors, they also found that "research mentors have the opportunity to provide technical, intellectual, and personal/emotional support, as well as professional socialization for students" (Kinner \& Lord, 2018, p. 19).

Echoing this sense of professional community and connection, Camacho et al. (2015) studied the Applied Mathematical Sciences Summer Institute (AMSSI) to discover what barriers existed between

Journal of the Scholarship of Teaching and Learning, Vol. 21, No. 1, April 2021. josotl.indiana.edu 
underserved populations and UREs. AMSSI was a program that focused on providing mathematical research experiences for women, underrepresented minorities, and individuals from small teaching institutions who might not have opportunities to do research otherwise. AMSSI used a mentoring model focused on "creating the learning community in which all individuals provided leadership to their own learning and the learning of others" (p. 65). Further, "presenting helped the students reinforce what they had learned, better understand their research problems, think on their feet, practice their oral presentation skills, and generate value" (p. 68). Russell, Hancock, and McCullough (2007) found that undergraduate research outcomes in minority groups showed increased understanding, confidence, and awareness about the rigors of graduate school. Barlow and Villarejo (2004) found that undergraduate research programs reduced attrition and greatly increased academic engagement in biological sciences, as well as the odds of positive graduation outcomes in minority student populations. Program participants were also more likely to pursue graduate study than were university graduates overall.

\section{UREs and Student Success}

Opportunities for UREs offer students numerous benefits, including increased self-confidence, career preparation, enhanced mentoring relationships, the development of transferable skills, networking opportunities, and collaboration skills (Faulconer \& Gruss, 2019). Bowman and Holmes (2018) explored the effect of 1st-year participation in research experiences on undergraduate grade point average (GPA), which showed that overall, 1st-year undergraduate research participation was positively related to 4th-year undergraduate GPA as well as 1st-year university satisfaction. Interestingly, 1st-year participation in this experience did not have a significant effect on students' 1styear GPA but rather an apparent delayed effect on 4th-year GPA. Fechheimer et al. (2011) found that students involved in undergraduate research (all students taking one or more directed-research courses) had a significantly higher GPA compared with students who did not participate in undergraduate research for all students, as well as for males and females separately. Harde and Haave (2012) argued that, typically, access to undergraduate research has been limited to students with superior GPAs. Few studies, however, have documented the impact on students in general with lower grades or whether the impact of undergraduate research on GPA is observable prior to graduation.

\section{Research Questions}

The institution currently under focus in this case study already had moderately strong UREs at the course and programmatic levels. The purpose of this case study was to examine this institution's struggle with creating a campus-wide community of research and inquiry. By creating the undergraduate research symposium, researchers hoped to find answers to the following research questions:

1. Will students who participated in an undergraduate research symposium be retained at higher rates from year to year than students who did not?

2. How does cumulative GPA differ in students who participated in an undergraduate research symposium versus students who did not?

3. How do rates of persistence/perseverance differ among students from various underserved and traditionally advantaged groups who presented in the symposium? Among nonparticipants?

4. How does participation in an undergraduate research symposium affect students' perceptions of their own learning? 


\section{Method}

We used a mixed methods approach to analyze how students' participation $(N=162)$ in an institutionwide undergraduate research symposium affected students' perceptions of their own learning, and if the integration of this event into the academic and social fabric of the college led to improvements in student success as represented by cumulative GPAs as well as, persistence/perseverance, and retention rates.

\section{Conceptual Model}

Astin's (1991) Input-Environment-Output model was the conceptual model that influenced the QEP Is HIP initiative to capture student data in a way that demonstrates an understanding of student qualities and characteristics upon their entry into the institution, the nature of the HIPs that potentially influence their learning and social environments, and their qualities and characteristics as they exit the institution, to be able to fully evaluate its effectiveness. Astin (1999) also created five basic assumptions about student involvement, one of which emphasizes the idea that what a student gains from being involved in a pursuit is directly related to the student's level of intensity and extent of involvement, in terms of both quality and quantity. Likewise, academic performance is directly correlated with the level of a student's involvement in various pursuits. To that end, we acknowledge that the variations in success and achievement that may have occurred during the time period being studied cannot necessarily be attributed directly to the impact of the QEP is HIP initiative. Other factors such as personal development and the environment outside of the initiative (and institution in general) may have also created changes that could influence measures of student success, persistence/perseverance, students' perceptions of their own learning, and retention. Nonetheless, this study's purpose is to explore the idea that its institution-wide URE is a contributing influence on these measures.

\section{Participants and Procedures}

Since the initiation of the institution's QEP in the fall of 2017, data have been collected and analyzed from three cohorts (2017-2018, 2018-2019, 2019-2020), capturing students ( $N=1,095)$ who entered as new students (1st-years and transfers) in each fall semester under its implementation period (Table 1). The student symposium participants who self-selected to present in the 2019 inaugural research day were an amalgamation of the fall 2017 and fall 2018 cohorts, specifically. We designated a control group from the 2016-2017 cohort (before the QEP was introduced),but the data sets were incomplete and rendered unusable. Therefore, only descriptive statistics were used to ascertain if a change occurred between cohort groups, and the label "nonsymposium" was used to delineate students from the fall 2017 and fall 2018 cohorts who did not self-select to present. Furthermore, the quantitative data (i.e., success, persistence/perseverance, and retention) used in this study are captured year-round from various sources by the QEP assessment committee as part of the initiative. Two phases of qualitative measures were implemented pre- and postsymposium, so that researchers could capture students' perceptions of their own learning.

Journal of the Scholarship of Teaching and Learning, Vol. 21, No. 1, April 2021. josotl.indiana.edu 
Table 1. Quality enhancement plan cohort demographics.

\begin{tabular}{llll}
\hline Variable & Cohort & & \\
\cline { 2 - 4 } & $2017-2018$ & $2018-2019$ & $2019-2020$ \\
\hline Total number & 351 & 338 & 406 \\
Entering 1st-years & 272 & 247 & 277 \\
Transfers & 79 & 91 & 129 \\
Male & 127 & 137 & 164 \\
Female & 224 & 201 & 242 \\
Commuters & 86 & 85 & 130 \\
Residential & 265 & 253 & 276 \\
African American & 49 & 39 & 60 \\
Hispanic and Latino/Latina & 25 & 13 & 2 \\
Multiracial & 12 & 15 & 2 \\
Pell eligible & 154 & 154 & 189 \\
\hline
\end{tabular}

Data and Identity Protections

In January 2018, a proposal was submitted to the Institutional Review Board (IRB) for the QEP is HIP initiative in anticipation of tracking measures related to the symposium event. The principal and coprincipal investigators completed their training with the Collaborative Institutional Training Initiative prior to submission of the application. IRB approval was granted in February 2018, which allowed the investigators to track cohort GPA, underserved status, participation in HIPs, and Grit Scale (Duckworth, Peterson, Matthews, \& Kelly, 2007) scores. In February 2020, an addendum was approved to create postevent focus groups of students who had presented in the symposium, 10 months later. Students were tracked using their student ID numbers so that data could be collected confidentially from the numerous databases across the college.

\section{Measures/Data Sources}

Cumulative GPA. Undergraduate cumulative GPA was collected for each student from the registrar's office at the end of each semester.

Retention data. Retention data were collected for each student from the Institutional Effectiveness and Research office at the end of each semester.

Grit (persistence/perseverance) scores. According to Duckworth et al. (2007), showing grit involves working vigorously toward challenges and maintaining effort and interest over years despite failure and adversity. Intertwined with grit is the concept of persistence or perseverance, or the voluntary continuation of a goal-directed action despite barriers or difficulties (Peterson \& Seligman, 2004). As part of the QEP initiative, the Grit Survey, taken directly from Duckworth's 12-item Grit Scale, is administered college-wide during a student's 1st and 4th years.

Postpresentation survey. For Phase 1 of the QEP, a simple follow-up online questionnaire was sent to the symposium participants $(N=162)$ from the 2017-2018 and 2018-2019 cohorts following the symposium event. The questionnaire asked one open-ended question, "Did this experience increase your interest in research, and if so, how? 
Ten-month postpresentation focus groups. For Phase 2, the researchers conducted a series of focus groups over a 2-day period, 10 months after the first annual symposium event, which also fell 6 weeks before the second annual symposium event. Participants had been recently exposed to symposium promotional materials and events around campus, and the topic was fresh in their minds. The QEP director and QEP Assessment Committee chair used institutional email to invite all previous symposium participants to participate in a focus group about their symposium experiences. Eighteen student participants were recruited and divided into four focus groups. Each focus group was asked the following eight questions:

1. What made you want to participate in undergraduate research or creative inquiry?

2. Did this experience increase your interest in research or creative work? How?

3. Have you been able to apply any research skills learned from this experience to your courses?

4. Did this experience have any effect on your communication skills? How?

5. Did this experience have any effect on your problem-solving skills? How?

6. Has this experience prepared you for your career and/or for graduate school? How?

7. Did someone serve as a mentor to you during this experience? If so, in what capacity and how did this help?

8. Are you or will you serve as a mentor to others who might want to participate in undergraduate research/creative inquiry? How would you help?

\section{Results}

\section{Influence on Student Retention}

The most striking result of this case study is the percentage of symposium participants who were retained from the 2018-2019 to the 2019-2020 academic year. In this study, the term retained was also used to indicate students who persisted to graduation. Students who presented in the undergraduate research symposium event $(n=162)$ were shown to be $15 \%$ more likely to graduate or be retained than those who did not $(n=555)$. The data in Figure 1 represents a subset of the total cohort population $(\mathrm{n}=717)$.

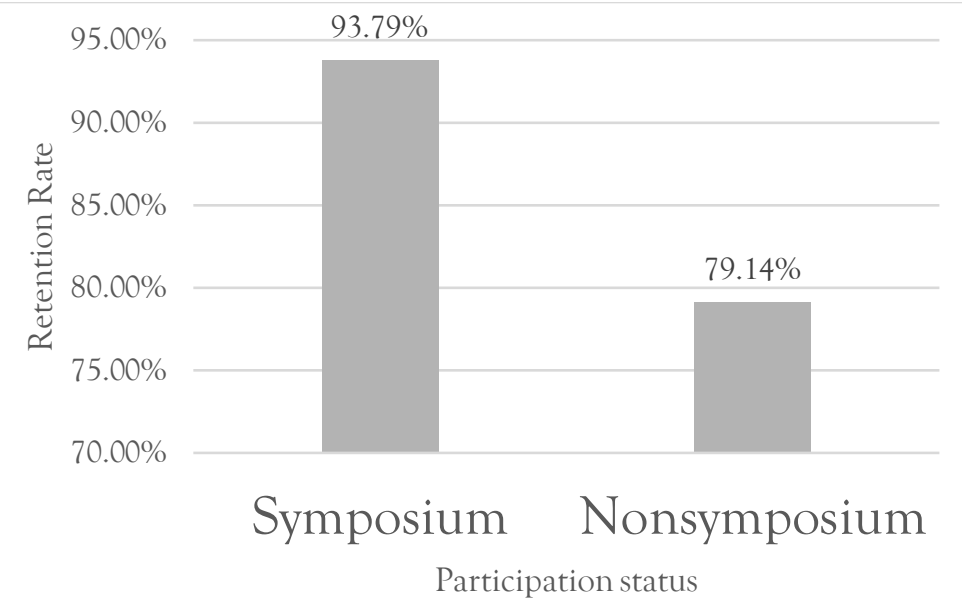

Figure 1. Total retention from the 2018-2019 to the 2019-2020 academic year. Symposium participants $(n=162)$ retained at a higher rate than nonsymposium participants $(n=555)$. 
As shown in Figure 2, when we examined the underserved populations to see what overall influence presenting undergraduate research at the symposium had, students who participated had a higher retention rate than nonparticipants regardless of their minority status, Pell eligibility, or firstgeneration status. The highest difference in retention rate $(22 \%)$ was for minority students $(n=144)$, followed by a difference of $11 \%$ for white students, $9 \%$ for first-generation students $(n=516)$ and $9 \%$ for the Pell-eligible students $(n=602)$. This again shows an increase in the rate of retention of underserved students who participate in a URE over those who do not. Students who did not selfreport their ethnicity or first-generation status were not included in this data set.

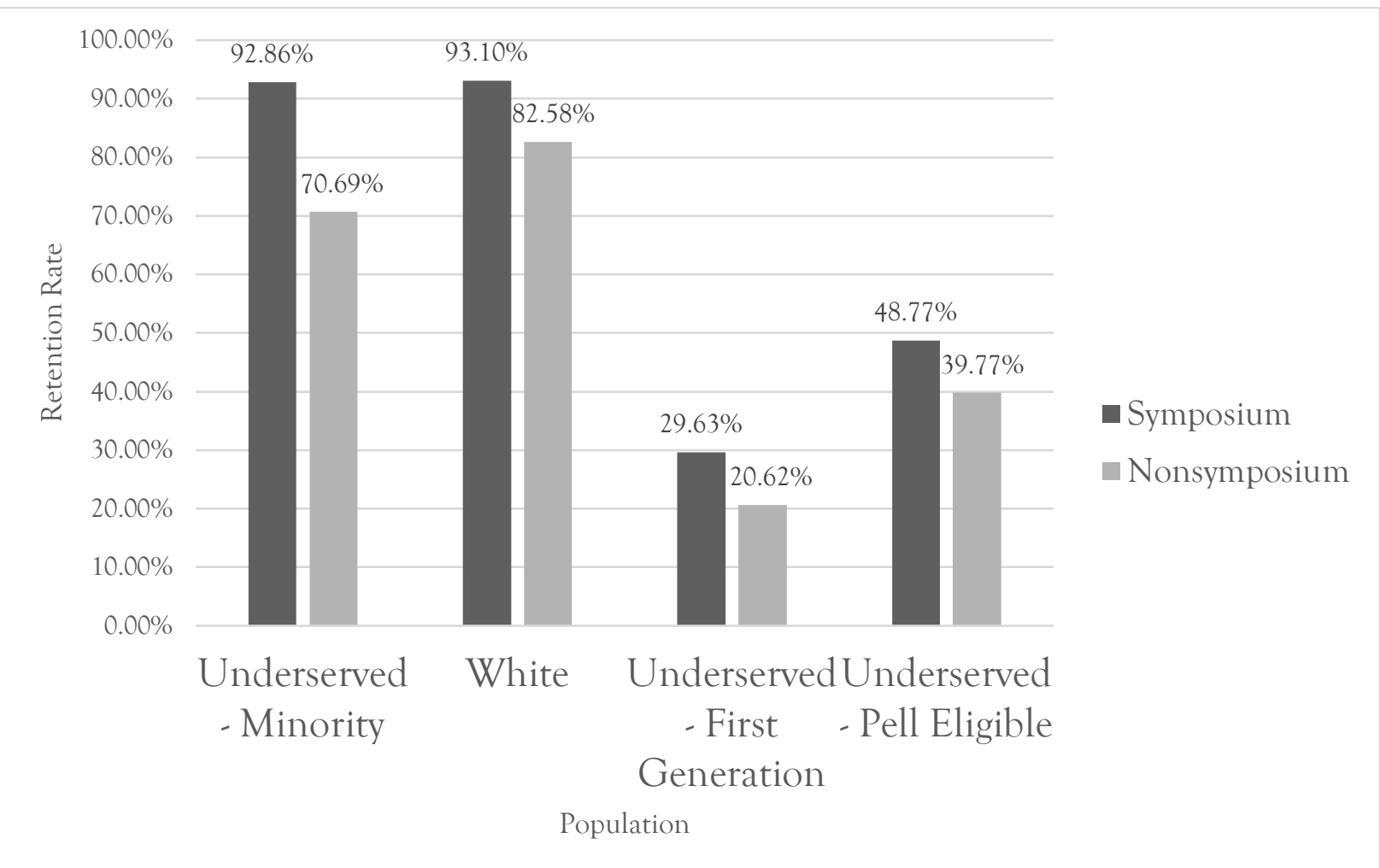

Figure 2. Retention rates of student populations disaggregated. Differences in retention rates between underserved and traditionally advantaged groups.

Influence on Student Success (GPA)

To determine if the symposium had any possible influence on student success, the researchers averaged the cumulative GPA of all symposium participants versus nonparticipants for the semester prior to the symposium as well as the semester after the symposium $(N=627)$. Students who participated in the symposium $(n=162)$ had a slightly higher cumulative GPA one semester later than students who did not $(n=555$, as shown in Figure 3. Cumulative GPA for students who persisted to graduation after the symposium was reflected by reporting the cumulative GPA of their last semester in attendance. 


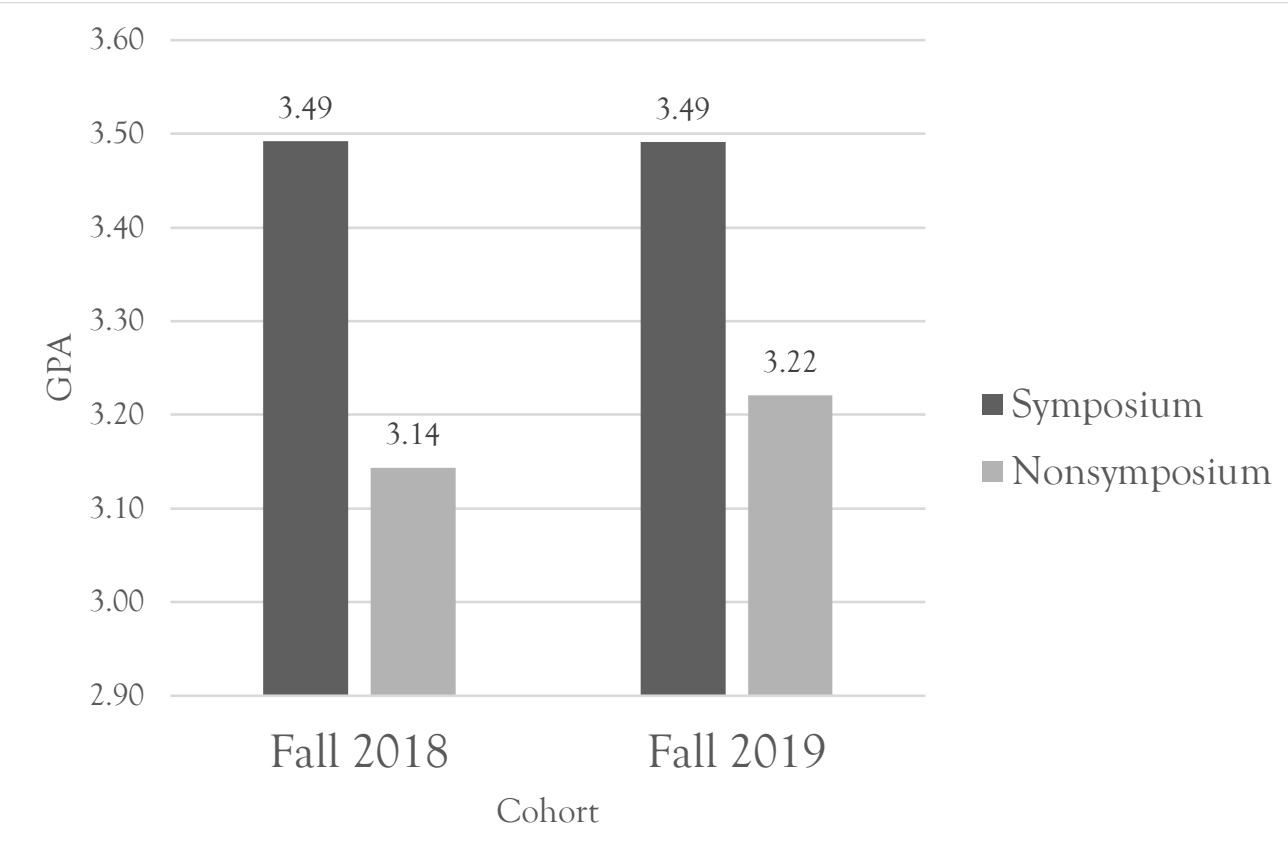

Figure 3. Cumulative grade point average (GPA) of participants and nonparticipants. Symposium participants averaged a higher GPA than nonparticipants.

\section{Influence on Student Persistence/Perseverance}

Grit scores were collected from students during their first semester at the institution and disaggregated to determine the influence on student persistence/perseverance $(N=280)$. Surprisingly, there was no recorded difference in the grit score of students who participated in the symposium $(n=162)$ versus those who did not $(n=118$; Figure 4). However, this data set is incomplete: Students who entered prior to fall 2017, most likely listed as a junior or senior during the semester of the symposium, were not administered the Grit Survey, because it was not yet implemented as part of the QEP assessment plan. As shown in Table 2, 74\% of symposium participants were recorded as juniors and seniors $(n=$ 120).

Table 2. 2019 Symposium participants.

\begin{tabular}{ll}
\hline Total number & 162 \\
\hline Retained/graduated & 155 \\
1st-year & 6 \\
Sophomore & 29 \\
Junior & 41 \\
Senior & 79 \\
Unknown & 7 \\
Underserved populations \\
Minority & 25 \\
Pell eligible & 79 \\
First generation & 48 \\
\hline
\end{tabular}

Journal of the Scholarship of Teaching and Learning, Vol. 21, No. 1, April 2021. josotl.indiana.edu 


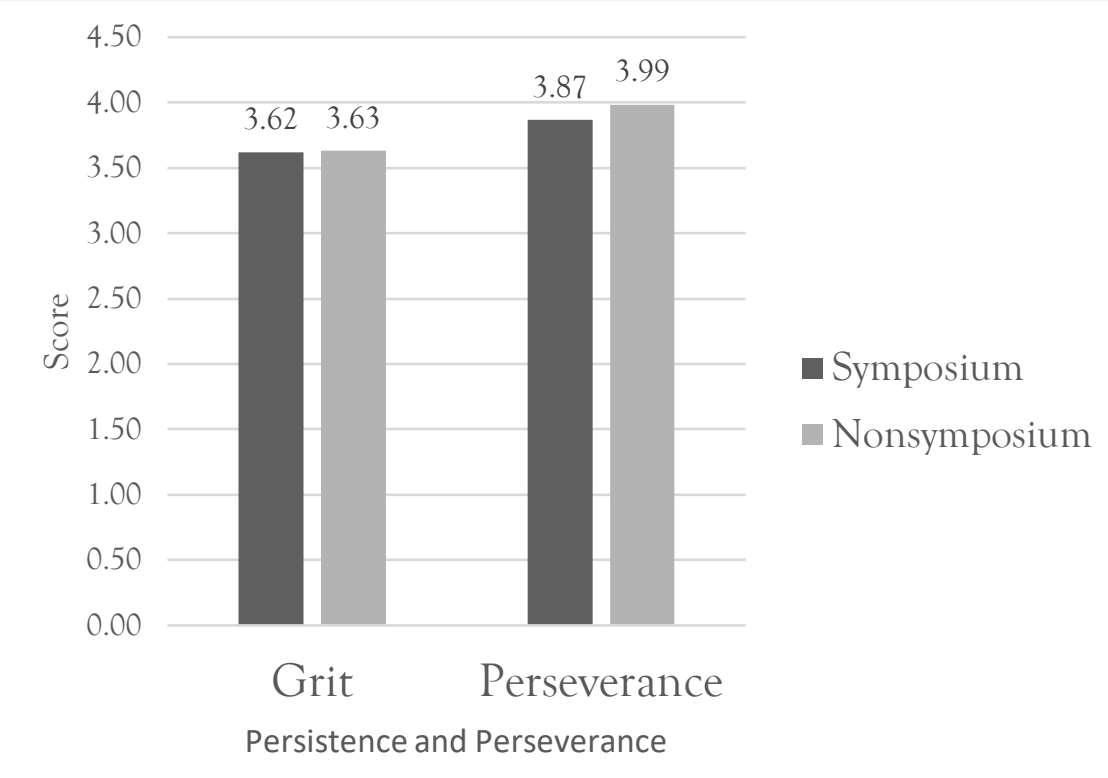

Figure 4. Student grit scores. No gains reported.

\section{Influence on Student Perceptions of Learning}

Phase 1. As part of the Phase 1 effort to determine what influence, if any, participating in the symposium had on students' own perceptions of learning, the researchers used the institution's own mobile app technology (campus cloud service) as a way to track participants and attendees as well as create a way to gain immediate feedback after the event's conclusion from a participant's perspective. The app offered a 1-5 (low to high) star rating system for the event and asked one open-ended question: "Did this experience increase your interest in research and if so, how?" Of all participants $(N=162), 158$ offered either 4 or 5 stars, and three offered qualitative feedback. These participants' remarks included: "Great first year! Looking forward to even more participation next year now that we've seen what it's like!" and "Yes it increased my interest! I thought it was very interesting how these students went through the whole research process and presented their results, just as I did."

Phase 2. Based on perceptions of learning outcomes as reported by participants in the 10month post event focus groups ( $N=18$ participants), four major themes emerged from among the recorded responses. The numbers in parentheses express the percentage of the total number of student respondents who reported these outcomes as gains:

1. Increased interest in research $(83 \%)$

2. Strengthened communication skills $(100 \%)$

3. Increased preparation for career/graduate school (77\%)

4. Interdisciplinary exposure $(61 \%)$

The following comment is typical and reflects the general tone of the responses that point to the increased interest in research that was gained by participating in the event:

I think it was a really good introduction into the world of research. I guess, presenting yourself as a professional academic person, who's doing research in these fields, and then presenting what you've learned and your ideas so far. I think it was a really good 
steppingstone like that had never occurred to me as something that I could do in my professional career. Now having that experience, I've thought more about it. I've thought about possible research topics.

Another participant noted, "I think for me it's encouraged me to do research in other parts of my life.... We went to a conference a month ago. Now I've started to think about maybe presenting at that conference and doing something in that field."

Interestingly, some students reflected that the experience was an expansion and continuation of their oral communication skills learned in earlier semesters. As one student put it:

I think, personally, I've done a lot of individual presentations, but I think this was my first time doing a group presentation, with a group made up of 12 people. It came to a point that we had to understand how we communicate within the team. How do we communicate to the external body? How do you switch when you communicate, and who is better at doing what? I think those skills really come out in communication as well. It's not the same thing as how you go and talk to a crowd. It's more like how do you prepare to talk to a crowd. That's something we learned, and it was a soft skill that we'll be using again.

When asked if participating had any influence on their preparation for careers or graduate school, many respondents commented that their leadership skills, soft skills, and preparation for graduate school rigor were increased. However, one student conveyed an epiphanic experience in selfawareness:

In terms of graduate school, I was a sophomore when I gave my presentation last year, and now I'm a junior, and I think [this] experience: it kind of made graduate school a reality for me. It was like, "Oh, I should probably start thinking about this. It's coming up." It opened that door for me, and as a result, I've thought about it a lot more. I've come to valuable conclusions about what I actually want to do with my life. I had to harshly ask myself, 'Okay, do I want to present on Philosophy and Art History for the rest of my life?' Turns out, the answer is no. Although it was great, and I find those things interesting, I don't think that's what I want to do for the rest of my life. So, learning that you don't want to do something is a valuable experience.

There were additional interesting outcomes that were outside the identified themes, including the importance of mentorship in the learning process, and perhaps most surprisingly, the emergence of an awareness of the work being done in other disciplines at the institution. As one student commented, "I think it's important. I know a lot of students here at the school; you get cliques of people in their major. This kind of thing opens up a lot awareness for others' areas of specialty."

\section{Discussion}

The purpose of this case study was to examine whether participation in an institution-wide undergraduate research symposium could help promote student engagement in research (particularly within underserved populations), retain students at higher rates, increase average GPA, and better prepare students for the rigors of professional careers/graduate school by increasing their persistence (grit) and perceptions of their own learning. In considering the findings, it is important to note that

Journal of the Scholarship of Teaching and Learning, Vol. 21, No. 1, April 2021. josotl.indiana.edu 
all UREs, whether at the course, program, or institutional level, are interrelated. Meaning, these findings are reflections of not just the event itself but also the culmination of student research, coursework, and projects leading up to the event. Additionally, it is important to point out that although this study did find that participation might have a positive influence on retention and GPA, these are not the only factors that impact these areas. While there was no apparent connection between the symposium participation and persistence, students did report an increased interest in research, strengthened communication skills, greater preparation for the rigors of professional careers/graduate school, and increased interdisciplinary exposure.

\section{Increased Interest in Research}

One common theme that emerged from the postsymposium focus groups was increased interest in research. This result and theme were what QEP facilitators hoped to gain from the symposium. The institution had previously maintained strong research opportunities for seniors in the form of required capstones, but this symposium allowed faculty the opportunity to redesign courses to incorporate research into 1st- and 2nd-year courses. This also allowed students to "own" more of their learning and consider their coursework in a broader context. Some students saw participation as a steppingstone and began to consider other opportunities for research. Others seemed to understand the connections between critical thinking, practical research skills, and communicating to a wider audience.

\section{Strengthened Communication Skills}

Frequently, students remarked on how participating in the symposium strengthened their communication skills and teamwork skills, which affirms Camacho et al.'s (2015) assertions that "presenting helped the students reinforce what they had learned, better understand their research problems, think on their feet, practice their oral presentation skills, and generate value" (p. 68). Because the institution does offer public speaking as part of the general education curriculum, many connected the soft skills acquired in that course with the demands of presenting in a larger forum. A few students commented on the experience as confidence building and associated presenting at the symposium with presenting their own work in a more professional or graduate school context.

\section{Preparation for Career/Graduate School}

A third theme that emerged was that the symposium experience had elements students associated with career/graduate school preparation. Students realized how important it was to develop their leadership skills and soft skills in preparation for their future career path. This affirms Russell et al.'s (2007) findings that undergraduate research outcomes lead to increased understanding, confidence, and awareness about the rigors of graduate school. Surprisingly, two student participants observed that graduate school is a real possibility, and this experience allowed them to make valuable decisions about their future career paths that probably would not have happened if they had not presented. This affirms Barlow and Villarejo's (2007) findings that URE participants are more likely to have a higher GPA as well as continue to graduate school. These students also remarked that they enjoyed the mentoring they received from working closely with a faculty member in their field of study. While determining the relationship between the symposium and mentorship was not an express goal of this study, this does help support Kinner and Lord's (2018) findings that "research mentors have the opportunity to provide technical, intellectual, and personal/emotional support, as well as professional socialization for students" (p. 19).

Journal of the Scholarship of Teaching and Learning, Vol. 21, No. 1, April 2021. josotl.indiana.edu 


\section{Interdisciplinary Exposure}

Building upon an established culture acknowledging the importance of undergraduate research at the course and programmatic levels, Phase 2 of this study added the additional reported theme of a "crosspollination" approach — as described by Craney et al. (2011)_among disciplines of the entire college. This interdisciplinary approach was encouraged by the undergraduate research symposium where students across the college were able to observe fellow students' presentations from all disciplines. While interdisciplinary exposure was not an explicit focus of the QEP steering committee, focusgroup participants did express a positive influence. This suggests future efforts of the QEP initiative should be more purposeful in providing opportunities for cross-pollination experiences to undergraduate students across the campus.

\section{Recommendations for Future Research}

Developing an institutional undergraduate research community of inquiry was a central theme of the QEP initiative in this study. Piedmont College considers itself a small liberal arts teaching college, as opposed to a research university, making this endeavor even more significant. Although the students are regularly exposed to research at the senior level through a capstone project in all disciplines, the goal was to infuse research into lower level courses to build a foundation of research and inquiry. Through the course of this study, the data indicated there may be higher retention rates and GPAs of symposium participants from one year to the next, regardless of ethnicity, Pell eligibility, or firstgeneration status. Of course, the inverse could potentially be true: Students with higher retention and GPAs are more likely to participate in the symposium. The next steps will include isolating these data points and developing a longitudinal study that determines causation when controlling for extraneous factors.

\section{Limitations}

During this study, some limitations were observed that echo Brownell and Swaner's (2009) concerns about assessing the impact of HIPs on student learning, despite the advantages of implementing these strategies. They contended that when measuring HIPs, it is " impossible to generalize ... or to identify which program component leads to a particular outcome" because of the various ways HIPs can be implemented at different institutions (p. 3). The same limitation applies to this particular case study, because there are numerous factors that can influence a student's matriculation, retention, and success.

Another limitation was the lack of complete data sets. The institution's Grit Survey was not administered until the fall of 2017 during the 1 st year of the QEP initiative. As a result, most symposium participants had not completed it, so the symposium's influence on persistence was difficult to determine. Additionally, some of the collected data on the underserved populations relied on students self-reporting their status; thus it was difficult to get a complete picture of the ethnic minority or first-generation status of all three cohorts. Because of these incomplete data sets, the researchers were unable to establish a control group so that inferential statistics could be conducted. Last, the researchers realized when conducting the focus groups that the question about student perceptions of problem-solving skills did not translate well to the participants. They answered the question with problem-solving skills they had to use on the day of the presentation (e.g., to deal with faulty technology, time management issues, etc.) and did not delve into any skills developed during their research. This question will be reworded for future focus groups.

Journal of the Scholarship of Teaching and Learning, Vol. 21, No. 1, April 2021.

josotl.indiana.edu 


\section{Conclusion}

Through the course of this study and the postsymposium evaluation, some positive institutional outcomes were illuminated. Just before the submission of this article, the QEP steering committee reported a doubling $(N=344)$ in the number of student participants and faculty mentors committed to presenting at the 2020 symposium. One of the four schools realized, after viewing the work of other schools at the symposium, that they did not have a strong research component in their major. As a result, they are working toward creating a more research-oriented capstone experience for their students, as well as examining how to integrate these experiences into their 1st- and 2nd-year courses. Furthermore, one department has not only developed a strong faculty/student mentorship as a result of this symposium experience but is now expanding this idea to allow the students to mentor peers from lower classes during their research. There was also a notable increase in conversation from various departmental faculty about exploring new ways to engage students, especially 1st- and 2ndyear students, in UREs. In sum, the main findings of this study aligned with principles of encouraging active participation in undergraduate research to create an institution-wide community of inquiry, meaningful contact between students and faculty, and a commitment to engaging in a culture of research across all disciplines.

\section{References}

American Association of Colleges and Universities. (2020). High-impact educational practices. A brief overview. https://www.aacu.org/leap/hips.

Astin, A. (1991). Assessment for excellence: The philosophy and practice of assessment and evaluation in higher education. New York, NY: MacMillan.

Astin, A. W. (1999). Student involvement: A developmental theory for higher education. Journal of College Student Development, 40(5), 518-529.

Barlow, A. E., \& Villarejo, M. (2004). Making a difference for minorities: Evaluation of an educational enrichment program. Journal of Research in Science Teaching, 41, 861-881. https://doi.org/10.1002/tea.20029

Bonet, G., \& Walters, B. (2016). High impact practices: Student engagement and retention. College Student Journal, 50(2), 224-235.

Bowman, N. A., \& Holmes, J. M. (2018). Getting off to a good start? First-year undergraduate research experiences and student outcomes. Higher Education, 76(1), 17-33. https://doi.org/10.1007/s10734-017-0191-4

Brownell, J. E., \& Swaner, L. E. (2009). High-impact practices: Applying the learning outcomes of literature to the development of successful campus programs. Peer Review 11(2), 26-30.

Camacho, E., Holmes, R., \& Wirkus, S. (2015). Transforming the undergraduate research experience through sustained mentoring: Creating a strong support network and a collaborative learning environment. New Directions for Higher Education, 63-73.

Cooper, K., Gin, L., Akeeh, B., Clark, C., Hunter, J., Roderick, T., ... Brownell, S. (2019). Factors that predict life sciences student persistence in undergraduate research experiences. PLoS ONE, 14(8), e0220186. https://doi.org/10.1371/journal.pone.0220186

Craney, C., McKay, T., Mazzeo, A., Morris, J., Prigodich, C., \& de Groot, R. (2011). Cross-discipline perceptions of the undergraduate research experience. The Journal of Higher Education, 82(1), 92-113. https://doi.org/10.1080/00221546.2011.11779086

Dhand, A., Luke, D. A., Carothers, B. J., \& Evanoff, B. A. (2016). Academic cross-pollination: The role of disciplinary affiliation in research collaboration. PLOS ONE, 11(1), e0145916. https://doi.org/10.1371/journal.pone.0145916

Journal of the Scholarship of Teaching and Learning, Vol. 21, No. 1, April 2021. josotl.indiana.edu 
Duckworth, A. L., Peterson, C., Matthews, M. D., \& Kelly, D. R. (2007). Grit Scale. PsycTESTS. Faulconer, E. K., \& Gruss, A. B. (2019). UNDERGRADUATE RESEARCH FOR ONLINE STUDENTS. Quarterly Review of Distance Education, 20(3), 45.

Fechheimer, M., Webber, K., \& Kleiber, P. B. (2011). How well do undergraduate research programs promote engagement and success of students? CBE Life Sciences Education, 10(2), 156-163. https://doi.org/10.1187/cbe.10-10-0130

Finley, A., \& McNair, T. B. (2013). Assessing underserved students' engagement in high-impact practices. Washington, DC: American Association of Colleges and Universities.

Harde, R., \& Haave, N. (2012). Wider horizons: Fostering a culture of undergraduate research. Collected Essays on Learning and Teaching, 5, 39-43.

Kelly, R. (2011). Implementing high-impact learning practices that improve retention. Recruitment and Retention in Higher Education, 25(12), 6-7.

Kinner, D., \& Lord, M. (2018). Student-perceived gains in collaborative, course-based undergraduate research experiences in the geosciences. Journal of College Science Teaching, 48(2), 48-58. https://doi.org/10.2505/4/jcst18_048_02_48

Kuh, G. (2008). High-impact educational practices: What they are, who has access to them, and why they matter. Washington, DC: American Association of Colleges \& Universities.

Nyhus, P., Cole, F., Yeterian, E., \& Firmage, D. (2002). Enhancing the integration of research and education using an interdisciplinary undergraduate research symposium. Council on Undergraduate Research Quarterly, 33, 16-23.

Peterson, C., \& Seligman, M. E. P. (2004). Character strengths and virtues: A handbook and classification. Washington, DC: American Psychological Association.

Russell, S., Hancock, M., \& McCullough, J. (2007). Benefits of undergraduate research experiences. Science, 316(5824), 548-549. https://doi.org/10.1126/science.1140384

Tinto, V. (1975). Dropout from higher education: A theoretical synthesis of recent research. Review of Educational Research, 45(1), 89-125. https://doi.org/10.3102/00346543045001089 